\title{
IMAGING MODALITIES FOR TEMPOROMANDIBULAR JOINT DISORDERS: AN UPDATE
}

\author{
DANIEL TALMACEANU ${ }^{1}$, LAVINIA MANUELA LENGHEL ${ }^{2}$, \\ NICOLAE BOLOG ${ }^{3}$, MIHAELA HEDESIU ${ }^{2}$, SMARANDA BUDURU ${ }^{4}$, \\ HORATIU ROTAR ${ }^{1}$, MIHAELA BACIUT ${ }^{1}$, GRIGORE BACIUT ${ }^{1}$
}

\author{
${ }^{1}$ Department of Cranio-Maxillofacial Surgery, Iuliu Hatieganu University of \\ Medicine and Pharmacy, Cluj-Napoca, Romania \\ ${ }^{2}$ Department of Radiology, Iuliu Hatieganu University of Medicine and Pharmacy, \\ Cluj-Napoca, Romania \\ ${ }^{3}$ Phoenix Swiss Med GmbH, Switzerland \\ ${ }^{4}$ Department of Prosthodontics, Iuliu Hatieganu University of Medicine and \\ Pharmacy, Cluj-Napoca, Romania
}

\begin{abstract}
The diagnosis and management of temporomandibular disorders (TMD) require both clinical and imaging examinations of the temporomandibular joint (TMJ). A variety of modalities can be used to image the TMJ, including magnetic resonance imaging (MRI), computed tomography (CT), cone beam CT, ultrasonography, conventional radiography. The present review outlines the indications of the most frequently used imaging techniques in TMD diagnosis.

Because of the anatomic complexity of the TMJ, imaging can be difficult. Choosing the proper imaging technique is essential. Conventional radiography, nowadays, is of limited interest. The use of flat plane films for TMJ pathology is not sufficient, because this joint requires three dimensional imaging views. Osseous changes are better visualized with CT and cone beam CT. Cone beam CT provides highresolution multiplanar reconstruction of the TMJ, with a low radiation dose, without superimposition of the bony structures. MRI is a noninvasive technique, considered to be the gold standard in imaging the soft tissue components of the TMJ. MRI is used to evaluate the articular disc in terms of location and morphology. Moreover, the early signs of TMD and the presence of joint effusion can be determined. High-resolution ultrasonography is a noninvasive, dynamic, inexpensive imaging technique, which can be useful in diagnosing TMJ disc displacements. The diagnostic value of highresolution ultrasonography is strictly dependent on the examiner's skills and on the equipment used.
\end{abstract}

Keywords: temporomandibular joint, temporomandibular disorders, computed tomography, magnetic resonance imaging, ultrasonography

\section{Temporomandibular joint anatomy}

The temporomandibular joint (TMJ) is a synovial joint whose common features are represented by a disc, two bones, a fibrous capsule, intra-articular fluid, a synovial

Manuscript received: 23.01.2018

Received in revised form: 05.02.2018

Accepted: 13.02.2018

Address for correspondence: danieltalmaceanu@yahoo.com membrane and ligaments [1]. The articular disc, a biconcave structure composed of dense fibrous connective tissue, is divided into a thicker anterior and posterior band and a thinner intermediate zone. Posteriorly, the disc is attached to the temporal bone by the retrodiscal tissue (bilaminar zone), highly vascularized and innervated. Anteriorly, the superior belly of lateral pterygoid muscle inserts onto the disc [2,3] (Figure 1). 


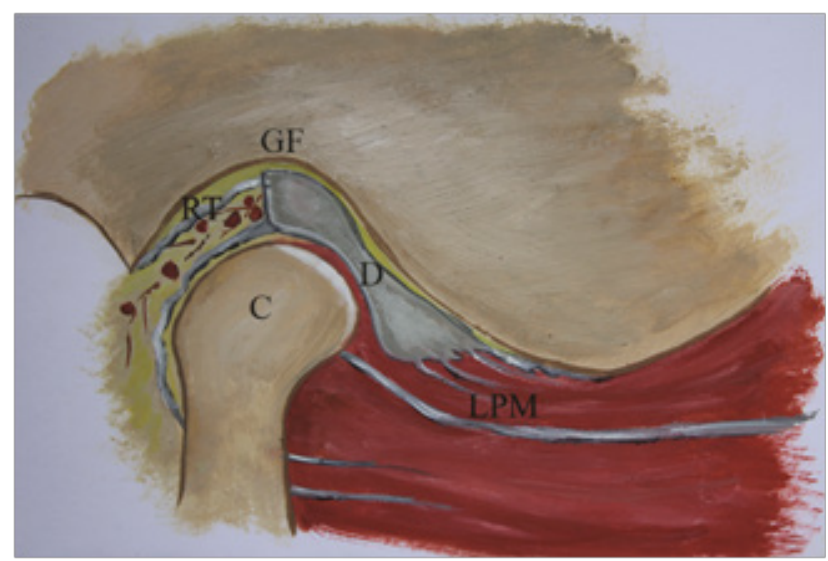

Figure 1. Temporomandibular joint anatomy: GF - glenoid fossa; C - mandibular condyle; D - articular disc; RT - retrodiscal tissue; LPM - lateral pterygoid muscle.

The TMJ is a ginglymoarthrodial joint, allowing a hinge-like movement, combined with an arthroidial, gliding motion. The hinge-like movement represents the first half of the mouth opening, whereas the sliding movement represents the second half, as well as the protrusion and lateral movements [4].

\section{Temporomandibular joint pathology}

TMJ pathology is complex and includes temporomandibular disorders (TMD), infections, tumors, traumatic lesions and growth development anomalies.

TMD is defined by the American Academy of Orofacial Pain (AAOP) as a complex term covering a number of clinical problems involving the masticatory muscles, the joint and the associated structures. The AAOP classifies the TMD in two groups: muscular and articular. The most common clinical signs of TMD are represented by pain, limited mouth opening and joint sounds (clicking, crepitation) [5]. In 2014, Research Diagnostic Criteria for Temporomandibular Disorders (RDC/TMD), clearly defined the different internal derangement conditions. According to $\mathrm{RDC} / \mathrm{TMD}$, two different degrees of displacement of the disc relative to the condyle exist: disc displacement with reduction and disc displacement without reduction [6].

The Piper disc classification [7] is also useful when dealing with internal derangements:1) Normal; 2) Ligaments or cartilage damage; 3a) Partial disc subluxation, with reduction; $3 b$ ) Partial disc subluxation, non-reducing; 4a) Complete disc dislocation, with reduction; 4b) Complete disc dislocation, non-reducing; 5a) No disc, bone to boneadapting; 5b) No disc, bone to bone- adapted.

\section{Temporomandibular joint imaging}

Although the clinical examination is the most important step in the diagnosis of TMJ pathology, special imaging techniques are needed due to the complex anatomy and pathology. It is very common to take an image of the joint when there is locking, pain and articular sounds. The clinician should properly decide which patients would need special imaging techniques depending on the clinical examination and individual selection criteria. One important thing to consider when imaging the TMJ is the interpretation of the joint function, which can be accomplished by comparing the condyle in the closed and opened mouth position. Several imaging techniques are available for TMJ visualization, as follows.

\section{Panoramic radiography}

It shows the jaws and the associated structures, being a helpful tool for the clinician in identifying any periodontal or odontogenic causes for orofacial pain. Panoramic radiography does not appear in the list of imaging techniques provided by RDC/TMD. Only the lateral part of the condyle can be assessed with this technique, being limited due to the superimposition of the zygomatic arch and the base of the skull [8]. Panoramic radiography can help evaluate the following:

- degenerative bone changes (only in late stages; it is inadequate for the early detection of osseous modifications);

- asymmetries of the condyles (Figure 2);

- hyperplasia, hypoplasia;

- trauma;

- tumors.

The panoramic radiography does not reveal the functional status of the joint and has a relatively low specificity and sensitivity when compared with CT $[8,9]$. Epstein et al [10] consider the clinical findings of greater relevance than panoramic images for patients with TMD. Nevertheless, some authors have suggested panoramic radiography as a good imaging modality for TMJ visualization [11]. Although morphological abnormalities of the condyle can be assessed with panoramic radiography, they do not necessarily represent a sign of TMD [12]. Variations of condylar shape are present among individuals. Moreover, changes in head position could affect the image of TMJ, simulating different bone abnormalities (flattening, osteophytes, asymmetries) [13]. Dahlstrom et al. [14] concluded that panoramic radiography is useful in detecting bony changes of the condyle, but when these changes are suspected, and the radiography is normal, CT should be performed.

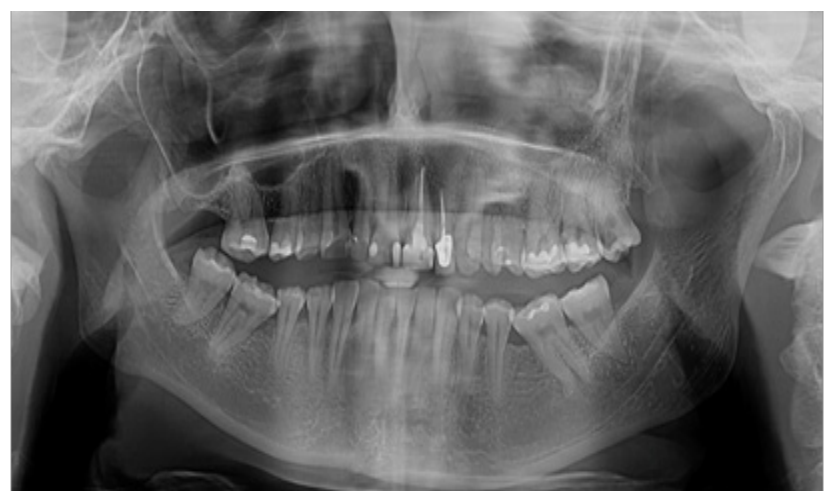

Figure 2. Panoramic radiography: important asymmetry between right and left mandibular condyle. 


\section{Plain radiography}

Consists of transcranial projection of TMJs. Different angulations are used to avoid the superposition of the temporal bone and the opposite TMJ: lateral oblique transcranial projections, anterior-posterior projections, submental-vertex projection, transpharyngeal view (Figure 3) [15]. Contact technique introduced by Parma is not recommended due to high radiation dose and superposition of bony structures (Figure 4). Plain radiography is useful in depicting degenerative joint disease in advanced stages [15]. The condyle position could also be assessed, but large variations of condyle position in the glenoid fossa were found, even in asymptomatic population [16,17]. Some studies have shown that the position of the condyle in the fossa is of little clinical significance [18]. Other studies suggest that the posterior position of the mandibular condyle in regard to the fossa, could represent an indirect sign of an anterior disc displacement [19-22]. The position of the head during the examination could influence the joint space, which could influence the interpretation of the radiography [23]. The use of flat plane films for TMJ pathology is not sufficient, because this joint requires three dimensional imaging views.
CT has been reported to be more suitable in identifying TMJ changes than conventional radiography [15].

\section{Computed tomography (CT)}

First used for TMJ evaluation in 1980 [24], CT is considered to be the best method for assessing osseous pathologic conditions of TMJ. It allows a multi planar reconstruction (sagittal, axial, coronal) of TMJ structures, obtaining 3D images in closed and opened-mouth positions. Signs of degenerative changes in the joint, like surface erosions, osteophytes, remodeling, subcortical sclerosis, articular surface flattening can be evaluated using CT [15]. Some studies have reported that radiographic changes in the joint are not always related to pain $[15,25,26]$. Therefore, some patients with osseous abnormalities may experience pain, others may be pain free. Changes in the shape and location of the loading zone can also be seen on CT. CT is the main radiological investigation for tumors, growth development anomalies and fractures (Figure 5). Basically, any CT examination of the TMJ should focus on the following: intactness of the cortex, normal size and shape of the condyles and their centered position in the fossa, the adequate joint spaces, centric relation loading zone.
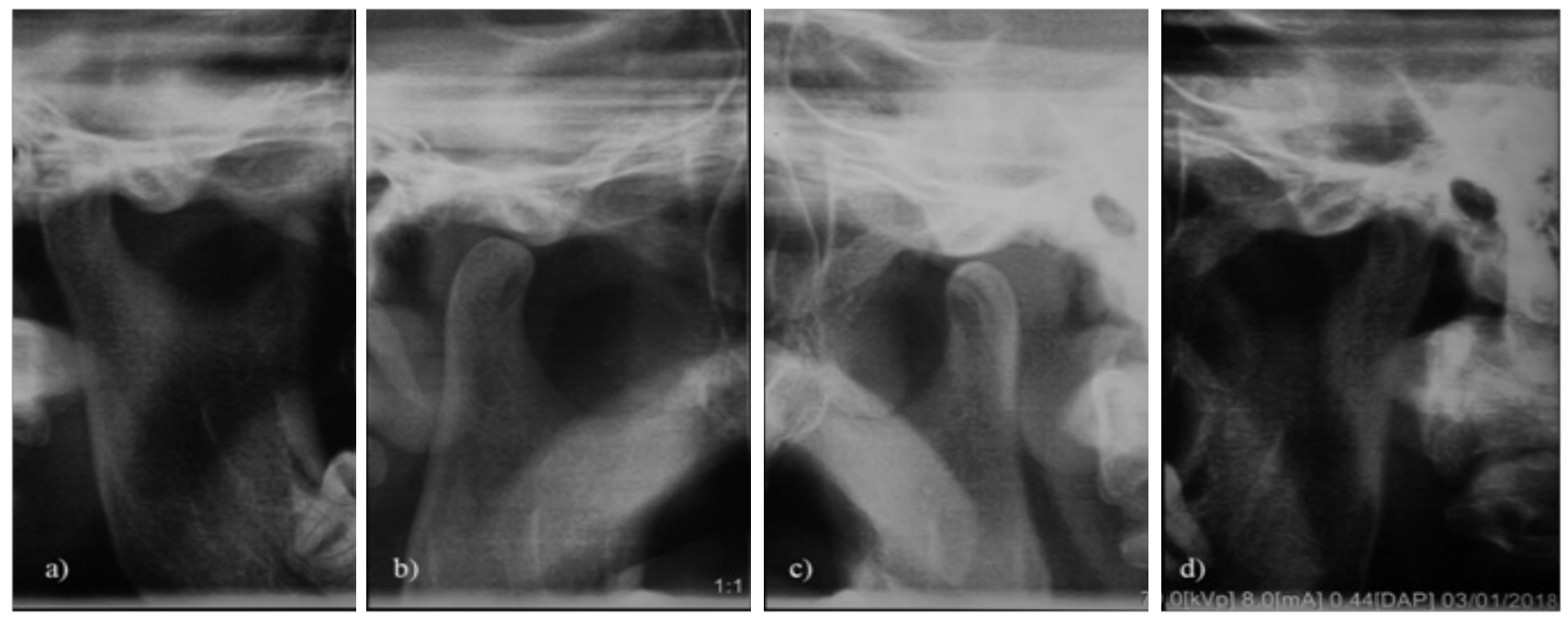

Figure 3. Comparative TMJ views obtained with a panoramic equipment: mouth-closed (a), (d) and mouth-opened (b), (c).
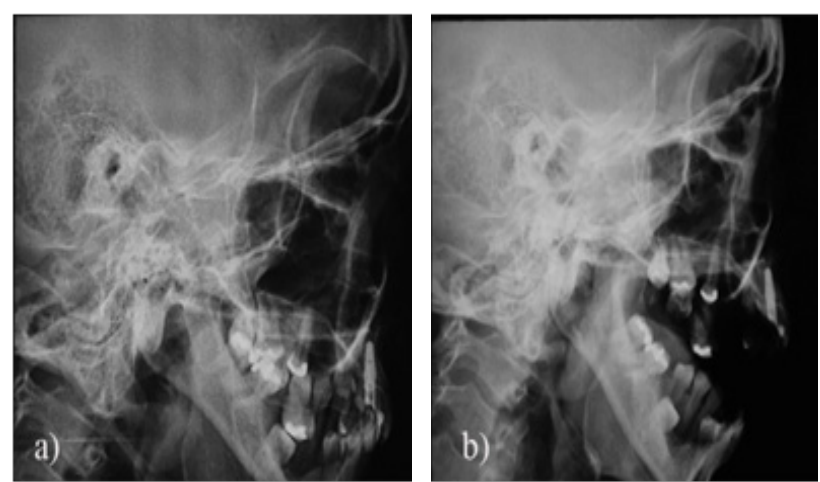

Figure 4. Contact technique (Parma incidence) of imaging the TMJ: mouth-closed (a), mouth-opened (b).
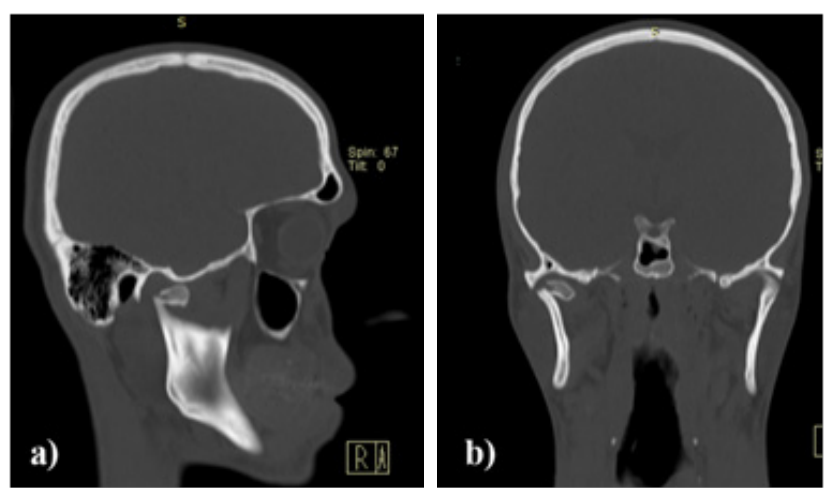

Figure 5. CT scan of an intracapsular fracture of the right TMJ. Sagittal plane (a), coronal plane (b). 
Autopsy studies performed for the assessment of condylar abnormalities showed better results for CT than MRI [27]. Wesetesson et al. [28] found a sensitivity of $75 \%$ and a specificity of $100 \%$ for the diagnosis of condylar bony changes. Regarding the visualization of the soft tissues of TMJ (disc, synovial membrane, ligaments, lateral pterygoid muscle), CT is not used as a primary diagnostic method. The disc could be visualized on CT scans only with injection of contrast media in the joint (arthrography). Arthrography is a dynamic investigation, but was never widely used, due to its invasiveness, pain and allergic reactions [29]. TMJ disc pathology and lateral pterygoid muscle pathology is better assessed with MRI. On CT scans, the position and the shape of the mandibular condyle in the glenoid fossa is well seen, though some authors suggest that this reference is not a precise sign of disc pathology [16-18,30].

The main disadvantage of $\mathrm{CT}$, compared to other radiological methods, is the high cost and the radiation exposure. Being introduced in TMJ evaluation in 1990s, cone beam CT (Figures 6 and 7) is widely available now and provides high-resolution multiplanar reconstruction of the TMJ [31,32]. The main advantage of cone beam CT, compared to CT, is the lower radiation dose to the patient [33-35]. The spatial resolution of cone beam $\mathrm{CT}$ is higher than that of conventional CT [36,37]. Studies developed by Hintze et al. [38] found no significant differences between conventional tomography and cone beam CT in the detection of morphological TMJ changes. Cone beam $\mathrm{CT}$ performs better than conventional radiography and is as good as conventional CT, allowing to depict early bony changes of TMJ $[39,40]$. A review published by Silvia Caruso et al [41] pointed out the main contributions of cone beam $\mathrm{CT}$ in the field of TMJ:

- allows the calculation of volume and surface of the condyle;

- improves qualitative analyses of condylar surface and
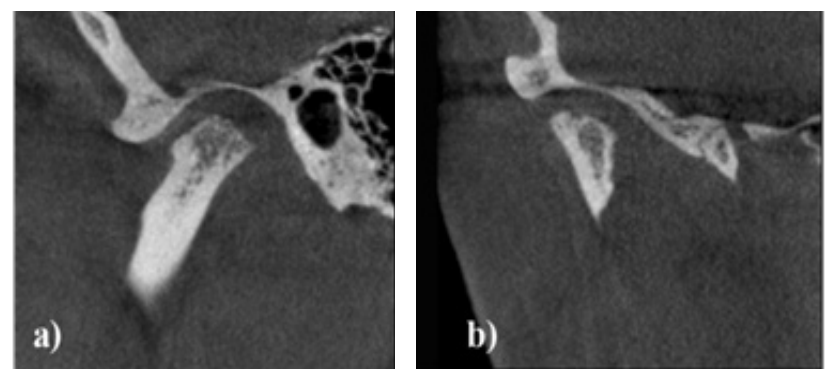

Figure 6. Cone beam CT of the right TMJ: flattening and erosions of the mandibular condyle. Sagittal plane (a), coronal plane (b). allows detecting the mandibular condyle shape;

- improves the accuracy of linear measurements of mandibular condyle;

- clarifies that, in case of facial asymmetry, the condyles are often symmetric, while joint space can change between the two sides;

- clarifies the position of the condyle in the fossa.

Although CT provides important information regarding the osseous components of TMJ, it has several limitations, like the artefact which can appear due to the patient's accidental movement during examination (especially in children). Also, a decrease in radiation dose (for cone beam $\mathrm{CT}$ ) can affect the image quality [32-38].

\section{Magnetic resonance imaging (MRI)}

MRI is currently considered the reference method for imaging the soft tissue structures of the TMJ (articular disc, synovial membrane, lateral pterygoid muscle) and has been pointed out as the best imaging modality in diagnosing disc displacements $[15,24,42-45]$. MRI could also detect the early signs of TMJ dysfunction, like thickening of anterior or posterior band, rupture of retrodiscal tissue, changes in shape of the disc, joint effusion [46].

Images can be obtained in all planes (sagittal, axial, coronal). In most scanning sequences, T1 weighted, T2 weighted and proton-density (PD) images are obtained. The PD images serve to visualize the disc-condyle relationship (Figure 8), while T2-weighted images are used in diagnosing inflammation in the joint $[47,48]$. The slice thickness is important for image quality. The most frequent used section thickness is $3 \mathrm{~mm}$. Reducing the slice thickness improves the quality of the images, but requires longer scanning time [45].

An axial localizing image is used to direct the long axis of the condyle in the closed-mouth position. Sagittal images are obtained perpendicular to the long axis of the condyle, and coronal images are obtained parallel to the long axis [49].
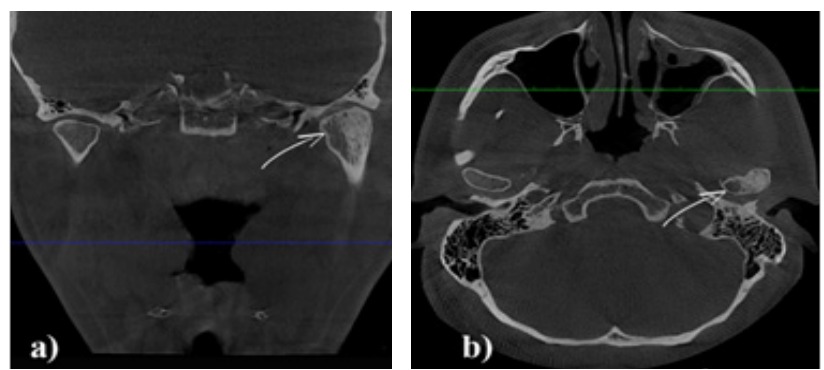

Figure 7. Cone beam CT of TMJ: left condyle hyperplasia (arrow). Coronal plane (a), axial plane (b).
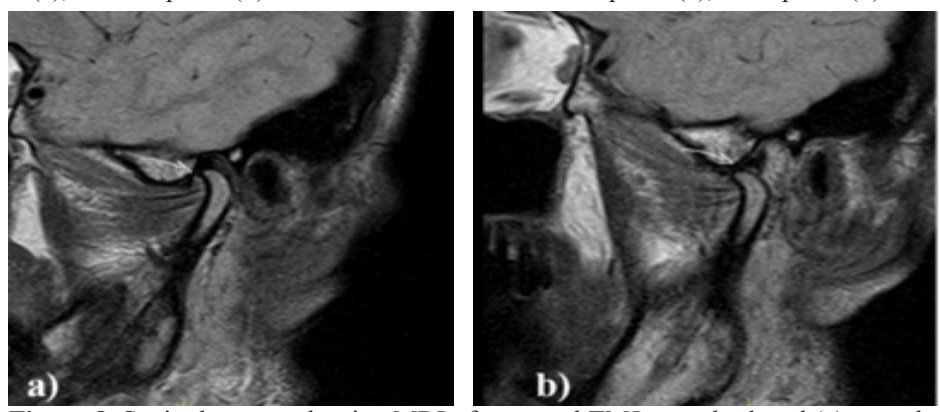

Figure 8. Sagittal, proton density, MRI of a normal TMJ: mouth-closed (a), mouthopened (b). The disc (arrow) is in a correct position. 
In MRI examination, a pathological condition is considered to be present relative to the intermediate zone of the meniscus (as a point of reference) and its interposition between the condyle and the temporal bone (Figure 9) [50]. Normal disc position, evaluated in the sagittal plane, is with the junction of posterior band aligned approximately at 12 o'clock, position relative to the condyle. Disc displacement is diagnosed when the posterior band sits in an anterior, posterior, medial or lateral position with regard to the condylar surface [51]. In the closed-mouth position, teeth should be in contact, whereas in the opened-mouth position, the jaw should be at the widest comfortable opening. This way, misinterpreted disc positions could be avoided [52].
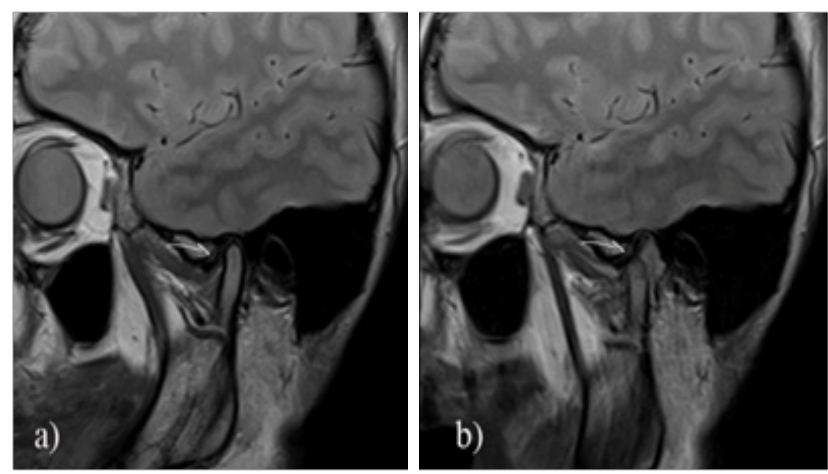

Figure 9. Sagittal, proton density, MRI of an anterior disc displacement with reduction: mouth-closed (a), mouth-opened (b). The displaced disc (arrow) returns to its normal position at maximal mouth opening.

Being a synovial joint, synovitis is a common situation and it is characterized by swelling due to hypertrophy of the synovia and overproduction of synovial fluid. Synovitis can be clearly visualized on MRI images [53]. Synovial inflammation could lead to joint effusion, defined as an increase in the volume of intra-articular fluid (Figure 10).

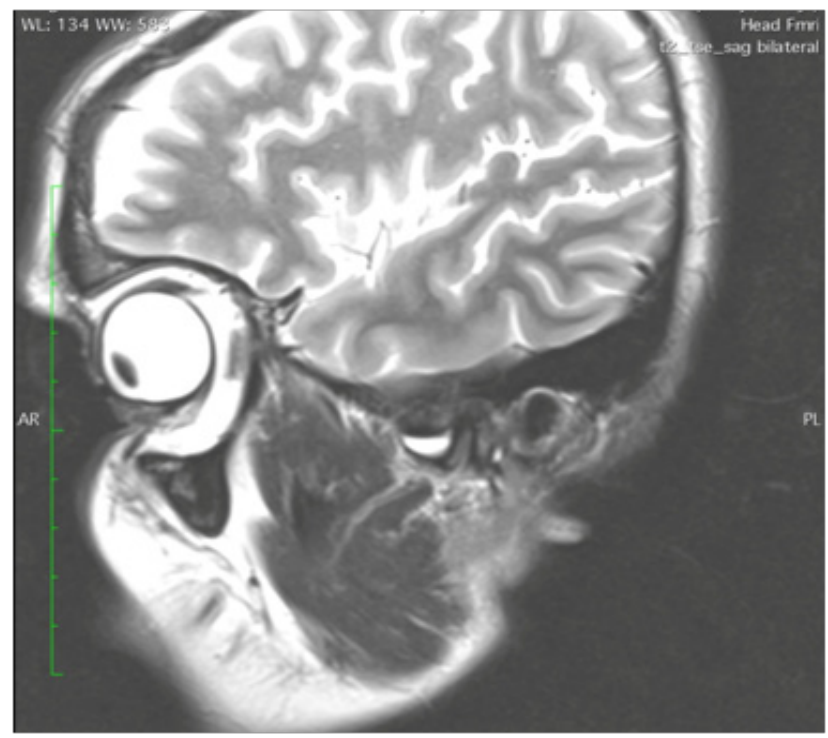

Figure 10. Sagittal, T2 weighted, MRI of a TMJ effusion.
Some studies have investigated the relationship between the articular eminence morphology and disc patterns in patients with disc displacements. The results showed that changes in the morphology of articular eminence (flattened) and disc could contribute to the appearance of disc displacement without reduction on that side [54]. Other studies also found changes in disc shape and dimension in cases of TMJ disc displacement [55].

Among the disadvantages of the MRI investigation, the following can be mentioned:

- it is costly and time consuming;

- restricted use in patients with claustrophobia;

- there is a possibility of missing the portion of condyle having a pseudo cyst [56];

- may miss different bone conditions and soft tissue calcifications with inflammatory diseases or tumors; in these cases, CT is the preferable imaging modality [57].

High-resolution ultrasonography

High-resolution ultrasonography (US) was first used for TMJ exploration in 1991, by Nabeih et al, using a $3.5 \mathrm{MHz}$ transducer [58]. Although it is a non-invasive, dynamic, inexpensive procedure, it is not commonly used in TMJ exploration. Being a real time investigation, it provides information about disc position, during mouth opening [59]. In the literature, contradictory levels of sensitivity and specificity were reported. These variable levels of sensitivity and specificity reported by the articles may be due to the different equipment used (different US frequencies). The use of high-resolution US (transducer at least $7.5 \mathrm{MHz}$ or higher) significantly increases the diagnostic value of this technique [60,61].

US examination is useful in depicting disc displacement and effusion. Normally, the disc is situated between two hyperechoic lines represented by the mandibular condyle and the articular eminence. If the disc is displaced in the closed-mouth position, the diagnosis is disc displacement. If the disc returns to its normal position during opening, the diagnosis is disc displacement with reduction (Figure 11). If not, the diagnosis is disc displacement without reduction (Figure 12) [59,62-64]. Regarding degenerative changes of the TMJ, US is still not recommended [65]. One difficulty of US is the possibility to obtain clear images, especially in the opened-mouth position, due to the overlying osseous structures. Another limitation of US is that the medial part of the disc cannot be visualized [59-65].

The diagnostic value of high-resolution US is strictly dependent on the examiner's skills and on the equipment used. Therefore, there is a continuous need for trained and experienced radiologists in this field. 

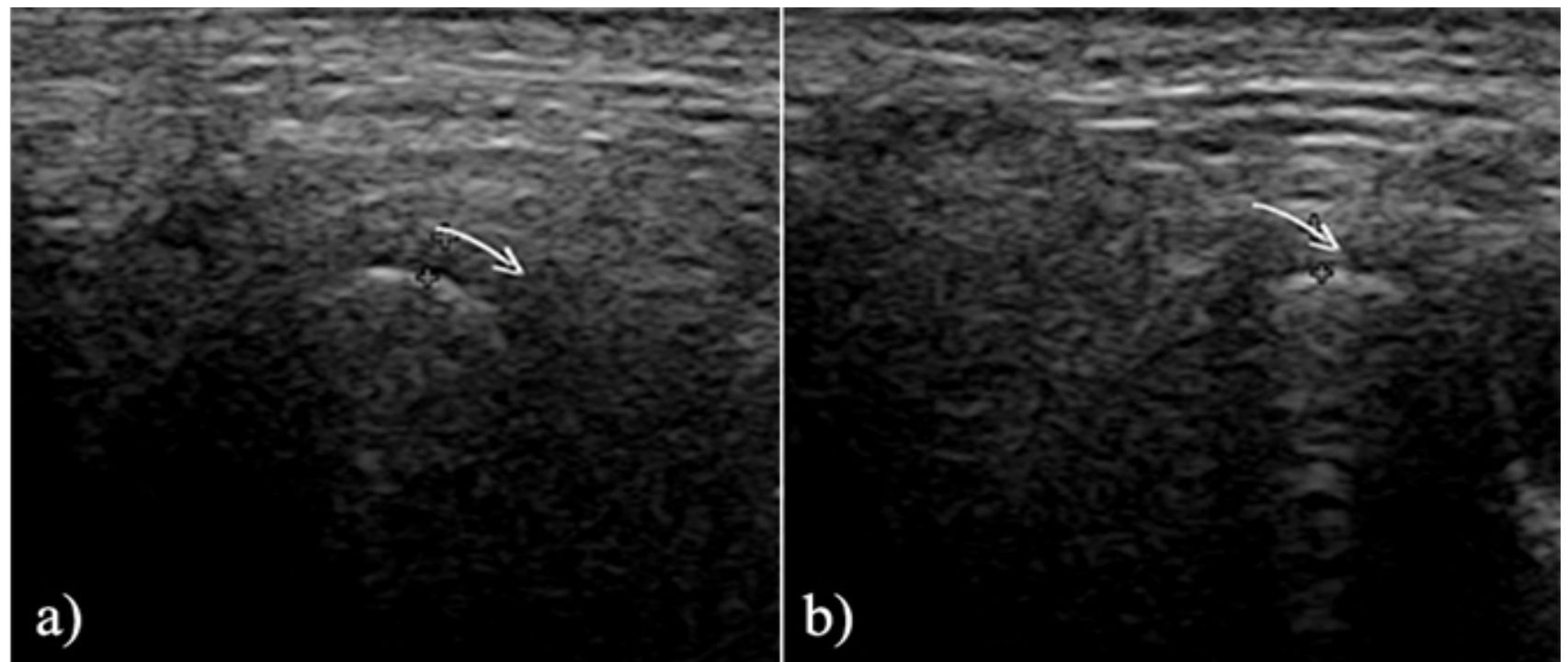

Figure 11. High-resolution US of an anterior disc displacement with reduction: mouth-closed (a), mouth-opened (b). The arrow shows the displaced disc.
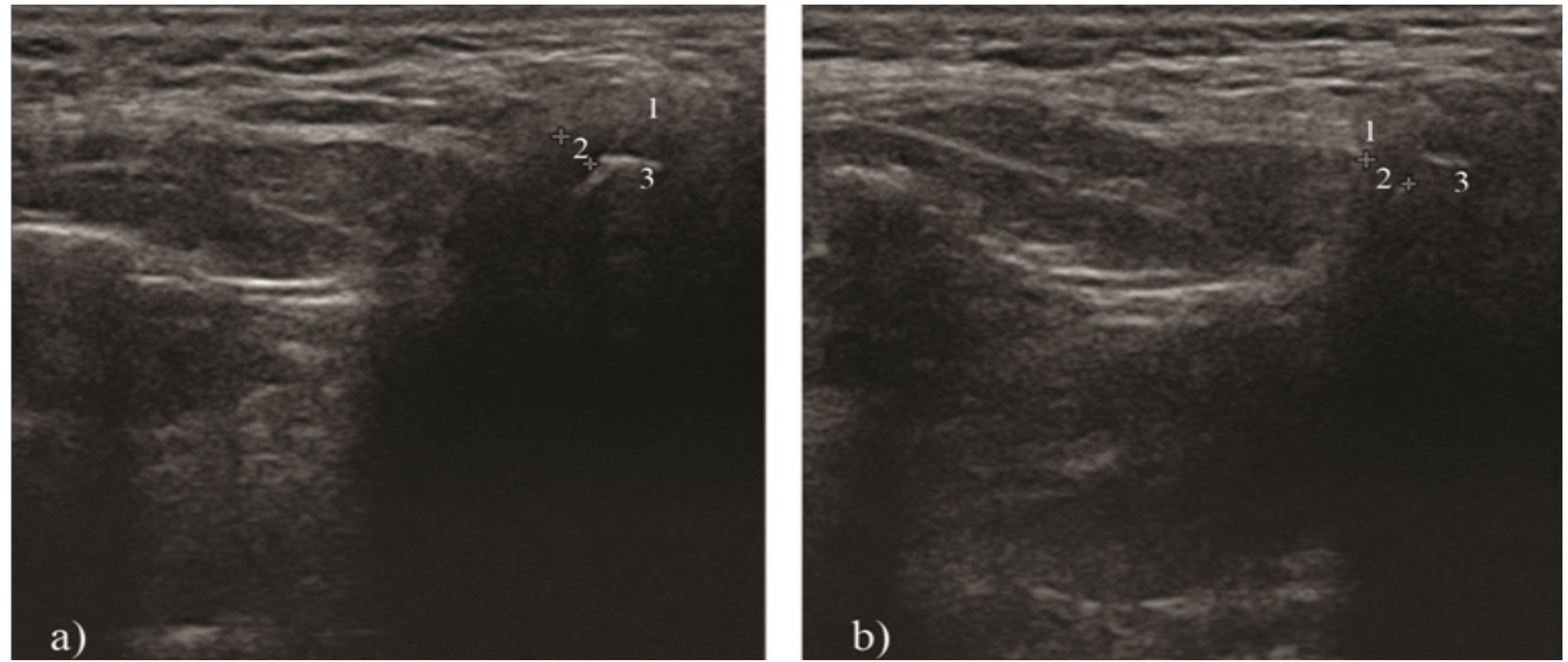

Figure 12. High-resolution US of an anterior disc displacement without reduction: mouth-closed (a), mouth-opened (b). 1 - articular eminence; 2 - articular disc; 3 - mandibular condyle.

\section{Conclusions}

The selection of the proper radiological technique for TMJ, as well as of the patient, must be carefully made by the practitioner, in correlation with the clinical signs and symptoms. The purpose of the chosen radiological investigation must improve the diagnosis and the treatment outcome according to each imaging examination's specific indications and varying degrees of sensitivity and specificity. CT and MRI are, nowadays, the most used imaging techniques. CT is the most efficient examination in detecting the osseous changes, whereas MRI remains the gold standard for the articular disc examination. Highresolution ultrasonography is a potential promising imaging diagnostic technique in assessing the TMJ disc position.

\section{Acknowledgements}

We would like to thank dr. Medeea Talmaceanu for the drawing of the temporomandibular joint anatomy.

\section{References}

1. Okeson JP. Management of temporomandibular disorders and occlusion. 6th ed. St. Louis: Mosby; 2008, pp 5-21.

2. Shaffer SM, Brismée JM, Sizer PS, Courtney CA. Temporomandibular disorders. Part 1: anatomy and examination/ diagnosis. J Man Manip Ther. 2014;22:2-12.

3 . Slavicek R. The masticatory organ: functions and dysfunctions. Gamma Meidizinisch-wissenschaftliche Forbildungs- GmbH, Klostenburg, 2006, pp 60-66.

4. Alomar X, Medrano J, Cabratosa J, Clavero JA, Lorente M, Serra I, et al. Anatomy of the temporomandibular joint. Semin 
Ultrasound CT MR. 2007;28(3):170-183.

5. De Leeuw R, Klasser G. Orofacial Pain: Guidelines for assessement, diagnosis and management. 5th ed. Chicago: Quintessence Publishing Co., Inc. 2013, pp 127-137.

6. Schiffman E, Ohrbach R, Truelove E, Look J, Anderson G, Goulet JP, et al. Diagnostic criteria for temporomandibular disorders (DC/TMD) for clinical and research applications: recommendations of the International RDC/TMD Consortium Network* and Orofacial Pain Special Interest Group $\dagger$. J Oral Facial Pain Headache. 2014;28:6-27.

7. Droter JR. An orthopaedic approach to the diagnosis and treatment of disorders of the temporomandibular joint. Dent Today. 2005;24(11):82, 84-88; quiz 88.

8. Ahmad M, Hollender L, Anderson Q, Kartha K, Ohrbach $\mathrm{R}$, Truelove EL, et al. Research diagnostic criteria for temporomandibular disorders (RDC/TMD): development of image analysis criteria and examiner reliability for image analysis. Oral Surg Oral Med Oral Pathol Oral Radiol Endod. 2009;107(6):844-860.

9. Poveda-Roda R, Bagan J, Carbonell E, Margaix M. Diagnostic validity (sensitivity and specificity) of panoramic X-rays in osteoarthrosis of the temporomandibular joint. Cranio. 2015;33(3):189-194.

10. Epstein JB, Caldwell J, Black G. The utility of panoramic imaging of the temporomandibular joint in patients with temporomandibular disorders. Oral Surg Oral Med Oral Pathol Oral Radiol Endod. 2001;92(2):236-239.

11. Brooks SL, Westesson PL, Eriksson L, Hansson LG, Barsotti JB. Prevalence of osseous changes in the temporomandibular joint of asymptomatic persons without internal derangement. Oral Surg Oral Med Oral Pathol. 1992;73(1):118-122.

12. Crow HC, Parks E, Campbell JH, Stucki DS, Daggy J. The utility of panoramic radiography in temporomandibular joint assessment. Dentomaxillofac Radiol. 2005;34(2):91-95.

13. Ruf S, Pancherz H. Is orthopantomography reliable for TMJ diagnosis? An experimental study on a dry skull. J Orofac Pain. 1995;9(4):365-374.

14. Dahlström L, Lindvall AM. Assessment of temporomandibular joint disease by panoramic radiography: reliability and validity in relation to tomography. Dentomaxillofac Radiol. 1996;25(4):197201.

15. Brooks SL, Brand JW, Gibbs SJ, Hollender L, Lurie AG, Omnell KA, et al. Imaging of the temporomandibular joint: a position paper of the American Academy of Oral and Maxillofacial Radiology. Oral Surg Oral Med Oral Pathol Oral Radiol Endod. 1997;83(5):609-618.

16. Pullinger AG, Hollender L, Solberg WK, Petersson A. A tomographic study of mandibular condyle position in an asymptomatic population. J Prosthet Dent. 1985;53:706-713.

17. Blaschke DD, Blaschke TJ. Normal TMJ bony relationship in centric occlusion. J Dent Res. 1981;60:98-104.

18. Paknahad M, Shahidi S, Iranpour S, Mirhadi S, Paknahad M. Cone-Beam Computed Tomographic Assessment of Mandibular Condylar Position in Patients with Temporomandibular Joint Dysfunction and in Healthy Subjects. Int J Dent. 2015;2015:301796. doi: 10.1155/2015/301796.

19. Paknahad M, Shahidi S. Association between mandibular condylar position and clinical dysfunction index. J Craniomaxillofac Surg. 2015;43(4):432-436.

20. Al-Rawi NH, Uthman AT, Sodeify SM. Spatial analysis of mandibular condyles in patients with temporomandibular disorders and normal controls using cone beam computed tomography. Eur J Dent. 2017;11(1):99-105.

21. Kurita H, Ohtsuka A, Kobayashi H, Hurashina K. A study of the relationship between the position of the condylar head and the displacement of the temporomandibular joint disk. Dentomaxillofac Radiol. 2001;30:162-165.

22. Ozawa S, Boering G, Kawata T, Tanimoto K, Tanne K. Reconsideration of the TMJ condylar position during internal derangement: comparison between condylar position on tomogram and degree of disk displacement on MRI. Cranio. 1999; 17(2):93-100.

23. Smith SR, Matteson SR, Phillips C, Tyndall DA. Quantitative and subjective analysis of temporomandibular joint radiographs. J Prosthet Dent. 1989;62:456-463.

24. Baba IA, Najmuddin M, Shah AF, Yousuf A. TMJ Imaging: A review. International Journal of Contemporary Medical Research. 2016;3(8):2253-2256.

25. Sano T, Westesson PL, Larheim TA, Takagi R. The association of temporomandibular joint pain with abnormal bone marrow in the mandibular condyle. J Oral Maxillofac Surg. 2000;58:254257.

26. Bertram S, Rudisch A, Innerhofer K, Pümpel E, Grubwieser G, Emshoff R. Diagnosing TMJ internal derangement and osteoarthritis with magnetic resonance imaging. J Am Dent Assoc. 2001;132:753-761.

27. Tanimoto K, Petersson A, Rohlin M, Hansson LG, Johansen CC. Comparison of computed with conventional tomography in the evaluation of temporomandibular joint disease: a study of autopsy specimens. Dentomaxillofac Radiol. 1990;19:21-27.

28. Westesson PL, Katzberg RW, Tallents RH, Sanchez-Woodworth RE, Svensson SA. CT and MR of the temporomandibular joint: comparison with autopsy specimens. AJR Am J Roentgenol. 1987; 148:1165-1171.

29. Maffe MF, Heffez L, Campos M, Backus P, Kahen HL, Langer $\mathrm{BG}$, et al. Temporomandibular joint: role of direct sagittal CT air-contrast arthrogram and MRI. Otorynogol Clin North Am. 1988;21:575-588.

30. Bonilla-Aragon H, Tallents RH, Katzberg RW, Kyrkanides S, Moss ME. Condyle position as a predictor of temporomandibular joint internal derangement. J Prosthet Dent. 1999;82(2):205-208. 31. Larheim TA, Abrahamsson AK, Kristensen M, Arvidsson LZ. Temporomandibular joint diagnostics using CBCT. Dentomaxillofac Radiol. 2015;44(1):20140235. doi: 10.1259/ dmfr.20140235.

32. Talaat W, Al Bayatti S, Al Kawas S. CBCT analysis of bony changes associated with temporomandibular disorders. Cranio. 2016;34(2):88-94.

33. Hedesiu M, Baciut M, Baciut G, Nackaerts O, Jacobs R; SEDENTEXCT Consortium. Comparison of cone beam CT device and field of view for the detection of simulated periapical bone lesions. Dentomaxillofac Radiol. 2012;41(7):548-552.

34. Oenning AC, Jacobs R, Pauwels R, Stratis A, Hedesiu M, Salmon B; DIMITRA Research Group, http://www.dimitra.be. Cone-beam CT in paediatric dentistry: DIMITRA project position statement. Pediatr Radiol. 2017 Nov 15. doi: 10.1007/s00247017-4012-9. [Epub ahead of print]

35. Almăşan OC, Băciuţ M, Hedeşiu M, Bran S, Almăşan H, Băciuţ G. Posteroanterior cephalometric changes in subjects with temporomandibular joint disorders. Dentomaxillofac Radiol. 2013;42(1):20120039. doi: 10.1259/dmfr.20120039.

36. Barghan S, Tetradis S, Mallya S. Application of cone beam 
computed tomography for assessment of the temporomandibular joints. Aust Dent J. 2012;57 Suppl 1:109-118.

37. Krishnamoorthy B, Mamatha NS, Kumar VA. TMJ imaging by CBCT: Current scenario. Ann Maxillofac Surg. 2013;3(1): 80-83.

38. Hintze $H$, Wiese $M$, Wenzel A. Cone beam CT and conventional tomography for the detection of morphological temporomandibular joint changes. Dentomaxillofac Radiol. 2007;36:192-197.

39. Honda K, Larheim TA, Maruhashi K, Matsumoto K, Iwai $\mathrm{K}$. Osseous abnormalities of the mandibular condyle: diagnostic reliability of cone beam computed tomography compared with helical computed tomography based on an autopsy material. Dentomaxillofac Radiol. 2006;35:152-157.

40. Honey OB, Scarfe WC, Hilgers MJ, Klueber K, Silveira AM, Haskell BS, et al. Accuracy of cone-beam computed tomography imaging of the temporomandibular joint: comparisons with panoramic radiology and linear tomography. Am J Orthod Dentofacial Orthop. 2007;132:429-438.

41. Caruso S, Storti E, Nota A, Ehsani S, Gatto R. Temporomandibular Joint Anatomy Assessed by CBCT Images. Biomed Res Int. 2017;2017:2916953. doi: 10.1155/2017/2916953. 42. Liedberg J, Panmekiate S, PeterssonA, Rohlin M. Evidence-based evaluation of three imaging methods for the temporomandibular disc. Dentomaxillofac Radiol. 1996;25:234-241.

43. Petersson A. What you can and cannot see in TMJ imaging-an overview related to the RDC/TMD diagnostic system. J Oral Rehabil. 2010;37(10):771-778.

44. Petscavage-Thomas JM, Walker EA. Unlocking the jaw: advanced imaging of the temporomandibular joint. AJR Am J Roentgenol. 2014;203(5):1047-1058.

45. Bag AK, Gaddikeri S, Singhal A, Hardin S, Tran BD, Medina JA, et al. Imaging of the temporomandibular joint: An update. World J Radiol. 2014;6(8):567-582.

46. Tomas X, Pomes J, Berenguer J, Quinto L, Nicolau C, Mercader JM, et al. MR imaging of temporomandibular joint dysfunction: a pictorial review. Radiographics. 2006;26(3):765781.

47. Kober C, Hayakawa Y, Kinzinger G, Gallo G, Yamamoto M, Sano T, et al. 3D-visualization of the temporomandibular joint with focus on the articular disc based on clinical T1-, T2-, and proton density weighted MR images. International Journal of Computer Assisted Radiology and Surgery 2007;2:203-210.

48. Sano T, Widmalm SE, Yamamoto M, Sakuma K, Araki K, Matsuda Y, et al. Usefulness of proton density and T2-weighted vs. T1-weighted MRI in diagnoses of TMJ disk status. Cranio. 2003;21(4):253-258.

49. Salé H, Bryndahl F, Isberg A. Temporomandibular joints in asymptomatic and symptomatic nonpatient volunteers: a prospective 15-year follow-up clinical and MR imaging study. Radiology. 2013;267:183-194.

50. Helms CA, Kaplan P. Diagnostic imaging of the temporomandibular joint: recommendations for use of the various techniques. AJR Am J Roentgenol. 1990;154:319-322.

51. Drace JE, Enzmann DR. Defining the normal temporomandibular joint: closed-, partially open-, and openmouth MR imaging of asymptomatic subjects. Radiology. 1990;177:67-71.

52. Gibbs SJ, Simmons HC 3rd. A protocol for magnetic resonance imaging of the temporomandibular joints. Cranio. 1998;16(4):236-241.

53. Rocabado M. Arthrokinematics of the temporomandibular joint. Dent Clin North Am. 1983;27(3):573-594.

54. Hirata FH, Guimarães AS, Oliveira JX, Moreira CR, Ferreira ET, Cavalcanti MG. Evaluation of TMJ articular eminence morphology and disc patterns in patients with disc displacement in MRI. Braz Oral Res. 2007;21(3):265-271.

55. Almăşan OC, Hedeşiu M, Băciuţ G, Leucuţa DC, Băciuţ M. Disk and joint morphology variations on coronal and sagittal MRI in temporomandibular joint disorders. Clin Oral Investig. 2013;17(4):1243-1250.

56. Sinha VP, Pradhan H, Gupta H, Mohammad S, Singh RK, Mehrotra D, et al. Efficacy of plain radiographs, CT scan, MRI and ultra sonography in temporomandibular joint disorders. Natl J Maxillofac Surg. 2012;3(1):2-9.

57. Larheim TA. Current trends in temporomandibular joint imaging. Oral Surg Oral Med Oral Pathol Oral Radiol Endod. 1995;80(5):555-576.

58. Nabeih YB, Speculand B. Ultrasonography as a diagnostic aid in temporomandibular joint dysfunction. A preliminary investigation. Int J Oral Maxillofac Surg. 1991;20:182-186.

59. Talmaceanu D, Lenghel LM, Bolog N, Popa Stanila R, Buduru S, Leucuta DC, et al. High-resolution ultrasonography in assessing temporomandibular joint disc position. Med Ultrason. 2018;20(1):64-70.

60. Manfredini D, Guarda-Nardini L. Ultrasonography of the temporomandibular joint: a literature review. Int J Oral Maxillofac Surg. 2009;38:1229-1236.

61. Kundu H, Basavaraj P, Kote S, Singla A, Singh S. Assessment of TMJ disorders using ultrasonography as a diagnostic tool: a review. J Clin Diagn Res. 2013;7:3116-3120.

62. Jank S, Rudisch A, Bodner G, Brandlmaier I, Gerhard $\mathrm{S}$, Emshoff R. High-resolution ultrasonography of the TMJ: helpful diagnostic approach for patients with TMJ disorders? J Craniomaxillofac Surg. 2001;29:366-371.

63. Jank S, Emshoff R, Norer B, Missmann M, Nicasi A, Strobl $\mathrm{H}$, et al. Diagnostic quality of dynamic high-resolution ultrasonography of the TMJ--a pilot study. Int J Oral Maxillofac Surg. 2005;34:132-137.

64. Habashi H, Eran A, Blumenfeld I, Gaitini D. Dynamic highresolution sonography compared to magnetic resonance imaging for diagnosis of temporomandibular joint disk displacement. J Ultrasound Med. 2015;34:75-82.

65. Emshoff R, Brandlmaier I, Bodner G, Rudisch A. Condylar erosion and disc displacement: detection with high-resolution ultrasonography. J Oral Maxillofac Surg. 2003;61:877-881. 